Microbes and Environments

Vol. 14, No. 3, $131-137,1999$

\title{
Isolation from Soil of Aerobic Chemoheterotrophic Bacteria Capable of Decomposing Methanethiol and Hydrogen Sulfide
}

\author{
Hiroshi Sato*1, Susumu Takakuwa ${ }^{2}$, Tamon Kimura ${ }^{1}$, Hitomi Shimomoto ${ }^{1}$, \\ TORU HIROSE ${ }^{1}$ and YASUSHI MORIYAMA ${ }^{1}$ \\ ${ }^{1}$ Fundamental Research Center, TOTO Ltd. Chigasaki, Kanagawa 253-8577, Japan \\ ${ }^{2}$ Department of Natural Science, Kyoto Women's University, Kyoto 605-8501, Japan
}

(Received August 17, 1998 -Accepted April 9, 1999)

\begin{abstract}
Twenty-eight strains of aerobic chemoheterotrophic bacteria capable of decomposing methanethiol and hydrogen sulfide were isolated from soil samples obtained from mountains, forests, farm fields, parks, hot springs, riversides, the seashore, pigpens, cowsheds, henhouses and other areas in Japan. Among the strains isolated, TOS-35 and TOS-55 had the greatest activities against both methanethiol and hydrogen sulfide. Based on physiological traits, strain TOS-35 was identified as a member of the genus Alcaligenes and strain TOS-55 as that of the genus Pseudomonas. Some authentic strains such as Pseudomonas putida IFO 3738, Comamonas testosteroni IFO 12048, Brevundimonas diminuta IFO 14213 and Burkholderia cepacia IFO 14595 were found to be capable of oxidizing methanethiol and hydrogen sulfide. Our results showed that many species of chemoheterotrophic bacteria in nature are capable of decomposing organic and inorganic sulfur compounds.
\end{abstract}

Key words: heterotrophs, methanethiol, hydrogen sulfide

Chemoautotrophic bacteria capable of metabolizing organic and inorganic sulfur compounds have been reported to belong to the genus Thiobacillus. For example, Kanagawa and Mikami ${ }^{7}{ }^{74)}$ reported the removal of methanethiol, dimethylsulfide and hydrogen sulfide from malodorous air by Thiobacillus thioparus TK-m. Ongcharit et al. ${ }^{10)}$ and Dalsgaard and $\mathrm{Bak}^{4)}$ described the oxidation of hydrogen sulfide by Thiobacillus denitrificans in continuous cultures. Wada et al. ${ }^{15)}$ reported the isolation from a peat biofilter of a Thiobachillus intermedius strain capable of oxidizing hydrogen sulfide.

However, few reports have dealt with chemoheterotrophic bacteria capable of oxidizing hydrogen

* Corresponding author; e-mail: hiroshi.sato@toto.co. jp sulfide and organic sulfur compounds. Suylen et $a l .{ }^{12)}$ showed that methylmercaptan oxidase was a key enzyme in the metabolism of methylated sulfur compounds in Hyphomicrobium EG. Zhang et al. ${ }^{16)}$ demonstrated the removal of dimethylsulfide, methanethiol and hydrogen sulfide by Hyphomicrobium sp. I55. Cho et al. ${ }^{2,3)}$ reported the oxidation of hydrogen sulfide to polysulfide by Xanthomonas sp. DY44.

Recently, we $\mathrm{e}^{13)}$ isolated aerobic chemoheterotrophs from various soil samples capable of decomposing organic sulfur compounds by the enrichment culture method. This report describes the isolation and partial characterization of the heterotrophs capable of oxidizing organic sulfur compounds. 


\section{Materials and Methods}

\section{Chemicals}

Dimethylsulfide (DMS) and sodium methylsulfide were purchased from Tokyo Kasei Kogyo Co. Ltd., Tokyo. Methanethiol (MT) and hydrogen sulfide (HS) were purchased as $1000 \mathrm{ppm}$ standard gases in $\mathrm{N}_{2}$ from Japan Air Liquid Co. Ltd., Tokyo. DTNB (5,5'-dithio-bis (2-nitrobenzoic acid)) was obtained from Sigma Chemical Co., St. Louis USA. All other chemicals used were commercially available and of chemically pure grade.

\section{Enrichment culture and isolation procedure}

Soil was collected from 71 grounds in 11 areas of Japan (Table 1). Approximately $20 \mathrm{mg}$ (wet weight) of soil was suspended in $15 \mathrm{ml}$ of sterile $10 \mathrm{mM}$ phosphate buffer $(\mathrm{pH} \mathrm{7.5)}$ and vortexed for $3 \mathrm{~min}$. After being allowed to stand for $5 \mathrm{~min}, 5 \mathrm{ml}$ of the supernatant was inoculated into $50 \mathrm{ml}$ of enrichment culture medium containing the following nutrients: 2 $\mathrm{g}$ of $\mathrm{Na}_{2} \mathrm{HPO}_{4} \cdot 2 \mathrm{H}_{2} \mathrm{O}, 2 \mathrm{~g}$ of $\mathrm{K}_{2} \mathrm{HPO}_{4}, 0.4 \mathrm{~g}$ of $\mathrm{NH}_{4} \mathrm{Cl}, 0.2 \mathrm{~g}$ of $\mathrm{CaCl}_{2}, 0.2 \mathrm{~g}$ of $\mathrm{MgCl}_{2}, 2 \mathrm{~g}$ of glucose and $740 \mu \mathrm{l}$ of DMS, per liter. Cultivation was done at room temperature for two weeks with gentle

Table 1. Occurrence of heterotrophs tolerant to DMS and capable of decomposing MT in soil samples obtained from various places.

\begin{tabular}{lccc}
\hline \multicolumn{1}{c}{ Areas } & $\begin{array}{l}\text { Number of } \\
\text { tested samples }\end{array}$ & DMS & MT \\
\hline Mountain & 4 & 32 & 2 \\
Forest & 3 & 15 & 1 \\
Farm field & 6 & 33 & 5 \\
Park & 8 & 48 & 3 \\
Hot spring & 9 & 23 & 4 \\
Riverside & 3 & 16 & 6 \\
Seashore & 1 & 5 & 1 \\
Pigpen & 3 & 6 & 0 \\
Cowshed & 22 & 76 & 0 \\
Henhouse & 9 & 0 & 0 \\
Others & 3 & 18 & 6 \\
Total & 71 & 272 & 28 \\
\hline
\end{tabular}

Abbreviations for activities are as follows: DMS, number of DMS-tolerant and/or -decomposing strains; MT, number of MT-decomposing strains. shaking. During the cultivation, $37 \mu 1$ of DMS was added on days 4 and 11.

Following the DMS-enrichment culture, $0.1 \mathrm{ml}$ of the supernatant was spread on tryptic soya (TS) agar medium and incubated for 1 to 3 days at $30^{\circ} \mathrm{C}$, and then colonies were isolated from the plate.

\section{Determination of MT- and HS-decomposing ac- tivities}

The isolated bacteria were cultured in TS liquid medium at $30^{\circ} \mathrm{C}$ for $12 \mathrm{~h}$ with shaking and then $5 \mathrm{ml}$ of the culture medium was transfered into $50 \mathrm{ml}$ of TS liquid medium and cultivated for a further $12 \mathrm{~h}$. After being washed, each strain was suspended and diluted in $100 \mathrm{mM}$ phosphate buffer ( $\mathrm{pH} 7.0$ ) containing $0.85 \% \mathrm{NaCl}$ to give an absorbance at $660 \mathrm{~nm}$ of approximately 0.2 (ca. $2 \times 10^{8}$ cells) in a serum-capped vial. The vial was continously bubbled with air containing $100 \mathrm{ppm}$ MT or HS at a flow rate of 100 $\mathrm{ml} / \mathrm{min}$ and incubated at $30^{\circ} \mathrm{C}$ for $10 \mathrm{~min}$ with gentle shaking.

The concentration of MT in the liquid phase was determined using Ellman's method modified by Grassetti and Murray'), and Ishiguro6). The reaction mixture in the vial was filtered through a Millipore filter (pore size: $0.45 \mu \mathrm{m}$ ), and $20 \mu \mathrm{l}$ of $10 \mathrm{mM}$ DTNB solution in $100 \mathrm{mM}$ phosphate buffer ( $\mathrm{pH} 7.0$ ) was added to $3 \mathrm{ml}$ of the filtrate and vortexed. The absorbance of the mixture at $412 \mathrm{~nm}$ was measured with a HITACHI MPS-2000 spectrophotometer. A quantitative curve was obtained using sodium methylsulfide as a standard. A linear relationship was observed between 0 and $2.5 \mathrm{mM}$ MT under the above analytical conditions.

The concentration of HS in the liquid phase was directly determined using an ORION EA920 ionmeter for the first $10 \mathrm{~min}$ and $6 \mathrm{~h}$ after the addition of $10 \mathrm{ml}$ of $1 \mathrm{M} \mathrm{NaOH}$ to $10 \mathrm{ml}$ of reaction mixture that had been incubated.

MT in the gas phase of the vial was measured, for the first $10 \mathrm{~min}$ and $24 \mathrm{~h}$ later by gas chromatography with a Hewlett Packard 5890 system equipped with a DB-17 column (J\&W, supplied by Yokogawa Analytical Systems, Tokyo) and a FPD detector $\left(200^{\circ} \mathrm{C}\right)$. HS in the gas phase was measured during the first $10 \mathrm{~min}$ and 
again $6 \mathrm{~h}$ later. The flow rate of the carrier gas was 1 $\mathrm{ml} / \mathrm{min}$ and the injection temperature was $150^{\circ} \mathrm{C}$. MT- and HS-decomposing activity are indicated by the residual amount of MT and HS in the gas phase.

\section{Identification and Characterization of MT- and HS-decomposing heterotrophs}

All isolates were examined by using a commercial Pile tube No. 2 identification kit (Nissui Pharmaceutical Co. Ltd., Tokyo) and BiOLOG MicroStation System $^{\mathrm{TM}}$ (BiOLOG Inc., USA., supplied by Gunze Sangyo, Tokyo). In addition, the physiological characteristics of the two strains with the most potent MTand HS-decomposing activities (TOS-35 and TOS-55) were examined in more detail. TOS-35 was examined by using a commercial ID test NF-18 identification kit (Nissui Pharmaceutical Co. Ltd., Tokyo). The characterization was based on Bergey's Manual of Determinative Bacteriology ${ }^{8)}$.

\section{Assay of Guanine + Cytosine $(G+C)$ contents}

Genomic DNA was isolated and purified from bacterial cells by the method of Birnboim and Doly ${ }^{1}$. The $\mathrm{G}+\mathrm{C}$ content of the DNA was determined by the HPLC method of Mesbah et al. ${ }^{9)}$. The HPLC system used was :column, a STR ODS-H column $(150 \times 4$ $\mathrm{mm}$, Shimazu), previously equilibrated with $0.2 \mathrm{M}$ $\mathrm{NH}_{4} \mathrm{HPO}_{4}$-acetonitrile $(40: 1 \mathrm{v} / \mathrm{v})$, at a flow rate of 1 $\mathrm{ml} / \mathrm{min}$ and a column temperature of $40^{\circ} \mathrm{C}$.

\section{Results and Discussion}

\section{Isolation of MT-decomposing heterotrophs}

As shown in Table 1, a total of 272 heterotrophic bacterial strains were isolated from 71 soil samples by DMS-enrichment culture. The MT-decomposing activity of the isolated strains was examined and 28 strains exhibited this activity.

None of the heterotrophic bacteria isolated from pigpen, cowshed and henhouse were capable of decomposing MT. Since the above three areas were located within institutions of stock raising, it was thought that antibacterial agents were frequently scattered on these grounds both to prevent epidemics and for deodorization.
Table 2 shows the MT- and HS-decomposing activities and generic assignment of the 28 strains. Sixteen strains were identified as Bacillus, 10 strains as Pseudomonas, one strain as Alcaligenes and one strain as Enterococcus. Five strains of Bacillus and one Enterococcus had strong MT-decomposing activity, but showed weaker HS-decomposing activity. In the case of Bacillus strains TOS-64 and TOS-182, however, the activities were reversed. Most of the Pseudomonas and Alcaligenes strains tested showed strong

Table 2. MT- and HS-decomposing activities and generic assignment of the isolated heterotrophic bacteria.

\begin{tabular}{lccl}
\hline Strain & MT & HS & generic assignment \\
\hline TOS-1 & +++ & + & Bacillus \\
TOS-3 & +++ & ++ & Bacillus \\
TOS-5 & +++ & + & Bacillus \\
TOS-7 & +++ & + & Bacillus \\
TOS-32 & ++ & + & Bacillus \\
TOS-60 & + & + & Bacillus \\
TOS-64 & + & +++ & Bacillus \\
TOS-72 & + & + & Bacillus \\
TOS-83 & + & + & Bacillus \\
TOS-93 & +++ & ++ & Bacillus \\
TOS-182 & + & +++ & Bacillus \\
TOS-207 & ++ & + & Bacillus \\
TOS-211 & + & + & Bacillus \\
TOS-213 & ++ & + & Bacillus \\
TOS-230 & ++ & +++ & Bacillus \\
TOS-254 & + & + & Bacillus \\
TOS-38 & +++ & + & Pseudomonas \\
TOS-52 & +++ & ++ & Pseudomonas \\
TOS-54 & +++ & ++ & Pseudomonas \\
TOS-55 & +++ & +++ & Pseudomonas \\
TOS-101 & ++ & + & Pseudomonas \\
TOS-104 & + & +++ & Pseudomonas \\
TOS-133 & +++ & +++ & Pseudomonas \\
TOS-227 & ++ & ++ & Pseudomonas \\
TOS-276 & ++ & ++ & Pseudomonas \\
TOS-283 & ++ & ++ & Pseudomonas \\
TOS-35 & +++ & +++ & Alcaligenes \\
TOS-130 & +++ & + & Enterococcus \\
Tbbevitis & + & + & + \\
TOS
\end{tabular}

Abbreviations for activities are as follows: MT, methanethiol decomposition; HS, hydrogen sulfide decomposition. Symbols indicate the decomposing activities (\%): + , less than $49 \%$;,$++ 50-89 \%$; +++ , more than $90 \%$. 
MT- and HS-decomposing activities. The difference of the activities between bacterial genera may be of interest.

Cho et al. ${ }^{2,3)}$ reported the isolation of a Xanthomonas strain capable of decomposing HS from peat. Wada et al. ${ }^{15)}$ reported the isolation of HS-oxidizing bacteria from a peat biofilter. From the results in Tables 1 and 2, however, it can be concluded that chemoheterotrophic bacteria capable of decomposing MT and HS occur widely in the environment.

\section{$M T$-decomposing activity versus HS-decomposing} activity of each isolate

The MT- and HS-decomposing activities measured in the gas phase of our isolates and some of the authentic strains obtained from the IFO culture collection are shown in Table 3.

All the isolates and authentic strains tested exihibited stronger MT-decomposing activities than Thiobacillus thioparus TK-m, which is a well-known MT-oxidizing chemoautotroph ${ }^{7}$. Strains TOS-35, TOS-55, and 4 authentic strains showed particulaly strong MT-decomposing activities. The comparison between MT-decomposing and HS-decomposing activity after $10 \mathrm{~min}$ revealed two types of heterotrophic bacteria. In the first group (group I), the MT-decomposing activity is higher than the HSdecomposing activity, as observed for strain TOS 35, Pseudomonas putida, Comamonas testosteroni, and Brevundimonas diminuta. We could not find any report on the MT- and HS-decomposing activity of Pseudomonas putida, Comamonas testosteroni, and Brevundimonas diminuta. In the second group (group II), both activities are almost the same as observed in strains TOS-38, TOS-52, TOS-54, TOS-55, TOS-101, TOS-130 and Burkholderia cepacia.

Most of the isolates and authentic strains but not TOS-101 decomposed MT in $24 \mathrm{~h}$. However, most isolates and authentic strains belonging to group II were unable to decompose HS in $6 \mathrm{~h}$ although strain TOS-55 could.

Smith and Kelly ${ }^{11)}$ proposed that MT and HS are intermediates in the metabolic pathway for DMS oxidation by Thiobacillus thioparus. According to them, potent MT-decomposing bacteria should also have potent HS-oxidizing activity. From Table 3, how-

Table 3. MT- and HS-decomposing activities of the isolated and IFO strains.

\begin{tabular}{|c|c|c|c|c|}
\hline \multirow{3}{*}{ Strain } & \multicolumn{4}{|c|}{ Residual conc. ${ }^{*}(\mathrm{ppm})$ after } \\
\hline & \multicolumn{2}{|c|}{ MT } & \multicolumn{2}{|c|}{ HS } \\
\hline & $10 \mathrm{~min}$ & $24 \mathrm{~h}$ & $10 \mathrm{~min}$ & $6 \mathrm{~h}$ \\
\hline Blank & 98.9 & 88.0 & 101.0 & 91.0 \\
\hline Thiobacillus thioparus TK-m & 60.0 & 22.2 & $\mathrm{ND}^{* *}$ & $\mathrm{ND}^{* *}$ \\
\hline \multicolumn{5}{|l|}{ group I } \\
\hline TOS-35 & 6.8 & 0.0 & 60.2 & 9.1 \\
\hline Pseudomonas putida & 16.0 & 0.0 & 74.4 & 0.0 \\
\hline Comamonas testosteroni & 8.7 & 0.0 & 64.5 & 0.0 \\
\hline Brevundimonas diminuta & 0.0 & 0.0 & 39.0 & 0.6 \\
\hline \multicolumn{5}{|l|}{ group II } \\
\hline TOS-38 & 48.1 & 5.0 & 63.0 & 60.0 \\
\hline TOS-52 & 50.7 & 3.4 & 60.5 & 43.9 \\
\hline TOS-54 & 46.3 & 1.8 & 61.5 & 47.9 \\
\hline TOS-55 & 53.0 & 0.0 & 55.7 & 1.1 \\
\hline TOS-101 & 105.7 & 11.5 & 70.6 & 69.8 \\
\hline TOS-130 & 92.4 & 2.4 & 69.4 & 60.0 \\
\hline Burkholderia cepacia & 55.7 & 0.0 & 85.4 & 85.1 \\
\hline
\end{tabular}

* The concentration in the gas phase.

** ND: Not determined. 
Table 4. Bacteriological characteristics of strain TOS-35.

\begin{tabular}{|c|c|}
\hline & TOS-35 \\
\hline \multicolumn{2}{|l|}{ 1. Morphological and cultural characteristics: } \\
\hline Shape & short rod \\
\hline Gram stain & - \\
\hline Motility & + \\
\hline Endospore & - \\
\hline Color of colonies on TS agar & white without soluble pigment \\
\hline Growth temperature & $5-30^{\circ} \mathrm{C}$ \\
\hline Growth $\mathrm{pH}$ & $5.0-11.5$ \\
\hline \multicolumn{2}{|l|}{ 2. Biochemical characteristics: } \\
\hline Litmas milk & alkaline (blue) \\
\hline Oxygen requirement & obligate aerobe \\
\hline GC mol\% of DNA & $54.1-57.8$ \\
\hline Poly- $\beta$-hydroxybutyrate accumulation & + \\
\hline Growth on MacConkey agar & + \\
\hline Setriamide agar & + \\
\hline OF test & - \\
\hline Voges-Proskauer test & - \\
\hline Methyl red test & - \\
\hline Hemolysis & + \\
\hline Pyocianin production & - \\
\hline Pyoverdine production & - \\
\hline Oxidase & + \\
\hline Catalase & + \\
\hline Urease & - \\
\hline Lipase (Tween 80 hydrolysis) & + \\
\hline Protease (gelatin liquefying) & - \\
\hline$\beta$-Galactosidase & - \\
\hline Phenylalanine deaminase & - \\
\hline Lysine decarboxylase & - \\
\hline Arginine dihydrolase & - \\
\hline Ornithine decarboxylase & - \\
\hline Nitrate reduction & - \\
\hline Nitrite reduction & + \\
\hline Anaerobic culture & - \\
\hline Penicillin tolerance & + \\
\hline \multicolumn{2}{|l|}{ Acid production from: } \\
\hline L-arabinose & - \\
\hline D-xylose & - \\
\hline \multicolumn{2}{|l|}{ Utilization of: } \\
\hline DL-lactate & + \\
\hline glutarate & $+\mathrm{w}$ \\
\hline phenyl acetate & + \\
\hline malonate & + \\
\hline azelate & - \\
\hline D-malate & - \\
\hline citrate & + \\
\hline acetate & + \\
\hline trans-aconitate & - \\
\hline DL-4-aminobutyrate & - \\
\hline pelargonate & - \\
\hline L-phenylalanine & + \\
\hline L-histidine & - \\
\hline L-aspartate & + \\
\hline L-leucine & + \\
\hline L-tyrosine & + \\
\hline ethanol & + \\
\hline 2,3-butanediol & - \\
\hline
\end{tabular}

Symbols indicate as follows: - , negative; + w, weak positive; + , positive; ND, Not determined. 
ever, it can be seen that the MT-decomposing activities of the strains are not directly proportional to their HS-decomposing activities, particularly in the cases of TOS-38, TOS-101, TOS-130 and Burkholderia cepacia IFO 14595. This result indicates that the metabolic pathway for MT oxidation in aerbic chemoheterotrophic bacteria is different from that in autotrophic bacteria. Further biochemical study of each isolate will be requred for the clarification of the decomposing pathway of MT and HS.

\section{Physiological traits of strains capable of MT- and HS- decomposition}

The taxonomical traits of strains TOS-35 and TOS-55, both of which had the strongest MT- and HS-decomposing activities, were investigated (Table 4). The colonies of strain TOS-35 on nutrient agar (NA) were white without soluble pigment, and emitted a strawberry-like odor. The strain was a Gram-negative obligately aerobic motile rod, lacked endospores, produced oxidase and catalase and was negative for oxidation-fermentation (OF) test. Strain TOS-35 could not utilize any of the sugars tested; including glucose, fructose, maltose, galactose, xylose, mannitol, sucrose, lactose, and esculin.

According to Bergey's manual ${ }^{8}$, the properties of strain TOS-35 were consistent with the genus $A l$ caligenes except for the hydrolysis of Tween 80 . The absolute likelihood score with the ID kit showing that strain TOS-35 is Alcaligenes feacalis was 0.829. The characteristics of strain TOS-35 coincided with those of $A$. feacalis JCM 2503 (the type strain) including the Tween 80 hydrolysis and the GC content. Strain TOS-35, therefore, was identified as Alcaligenes feacalis.

The colonies of strain TOS-55 on nutrient agar (NA) were pale cream-colored without soluble pigment. It was a Gram-negative, obligately aerobic motile rod, lacked endospores, produced oxidase and catalase, and was positive for OF (oxidation). Other characteristics were as follows: growth temperature, 10-30 ${ }^{\circ} \mathrm{C}$; growth $\mathrm{pH}, 4.0-10.5$; Litmus milk, alkaline; oxygen requirement, obligate aerobe; growth on MacConkey agar, positive; poly- $\beta$-hydroxybutyrate accumulation, positive; hemolysis, positive; arginine dihydrolase, positive; penicillin tolerance, positive; acid from L-arabinose, D-xylose, positive; utilization-positive, glucose, 2 -ketogluconate, $\beta$-alanine, L-arginine, DL-lactate, glutarate, D-malate, transaconitate, DL-4-aminobutyrate, L-phenylalanine, L-leucine, L-tyrosine, ethanol, 2,3-butanediol, malonate, L-histidine; Voges-Proskauer test, negative; methyl red test, negative; anaerobic culture, negative; denitrification, negative; trehalose, mesoinositol, azelate utilization-negative.

According to Bergey's manual ${ }^{8}$, these properties of TOS-55 were similar to those of Pseudomonas sp. In addition, TOS-55 showed high similarity to Pseudomonas putida based on the data from the BiOLOG MicroStation System ${ }^{\mathrm{TM}}$, which evaluates 95 carbon utilization tests (similarity score 0.862 ). Although a more precise study is needed to identify strain TOS-55, it is highly possible that TOS-55 belongs to the genus Pseudomonas. More detailed systematic studies of strains TOS-35 and TOS-55 are in progress and will be described elsewhere.

A section of the results presented here was announced at the Annual Meeting of the Japanese Society for Culture Collection, 1995.

\section{Acknowledgements}

The author is grateful to Professor Kenji Watanabe and Dr. Yukihiko Nakashima (Fukuoka University, Faculty of Pharmaceutical Sciences) for kind advice.

\section{References}

1) Birnboim, H.C. and J. Doly. 1979. A rapid alkaline extraction procedure for screening recombinant plasmid DNA. Nucleic Acids Res. 7: 1513-1523.

2) Cho, K.S., I. Kuniyoshi, M. Hirai and M. Shoda. 1991. A newly isolated heterotrophic bacterium, Xanthomonas sp. DY44, to oxidize hydrogen sulfide to polysulfide. Biotechnol. Lett. 13: 923-928.

3) Cho, K.S., M. Hirai and M. Shoda. 1992. Degradation of hydrogen sulfide by Xanthomonas sp. strain DY44 isolated from peat. Appl. Environ. Microbiol. 58: 1183-1189.

4) Dalsgaard, T. and F. Bak. 1992. Effect of acetylene on nitrous oxide reduction and sulfide oxidation in batch and gradient cultures of Thiobacillus 
denitrificans. Appl. Environ. Microbiol. 58: 1601-1608.

5) Grassetti, D.R. and J.F. Murray, JR. 1967. Determination of sulfhydryl groups with $2,2^{\prime}$ - or $4,4^{\prime}$ dithiodipyridine. Arch. Biochem. Biophys. 119: 41-49.

6) Ishiguro, M. 1985. in "SH-ki no kagakushushoku" Vol.8, ed. by Gakkai Shuppan Center.pp.90-97. (in Japanese)

7) Kanagawa, T. and E. Mikami. 1989. Removal of methanethiol, dimethyl sulfide, dimethyl disulfide, and hydrogen sulfide from contaminated air by Thiobacillus thioparus TK-m. Appl. Environ. Microbiol. 55: 555-558.

8) Holt, J.G., N.R. Krieg, P.H.A. Sneath, J.T. Staley and S.T. Williams. 1994. Bergey's manual of Determinative bacteriology, 9th Ed. Williams \& Wilkins, Baltimore.

9) Mesbah, M., U. Premachandran and W.B. Whitman. 1989. Precise measurement of the $\mathrm{G}+\mathrm{C}$ content of deoxyribonucleic acid by high-performance liquid chromatography. Int. J. Syst. Bacteriol. 39: 159-167.

10) Ongcharit, C., K.L. Sublette and Y.T. Shah. 1991. Oxidation of hydrogen sulfide by flocculated Thiobacillus denitrificans in a continuous culture. Biotech. Bioeng. 37: 497-504.
11) Smith, N.A. and D.P. Kelly. 1988. Mechanism of oxidation of dimethyl disulfide by Thiobacillus thioparus strain E6. J. Gen. Microbiol. 134: 3031-3039.

12) Suylen, G.M.H., P.J. Large, J.P. Van Dijken and J.G. Kuenen. 1987. Methyl mercaptan oxidase, a key enzyme in the metabolism of methylated sulphur compounds by Hyphomicrobium EG. J. Gen. Microbiol. 133: 2989-2997.

13) Takakuwa, S. and H. Sato. 1997. Isolation of heterotrophs capable of decomposing methanethiol and hydrogen sulfide from soil. Proc. 6th ChinaJapan Int. Congr. Microbiol. pp.101-102.

14) Tanji, Y., T. Kanagawa and E. Mikami. 1989. Removal of dimethyl sulfide, methyl mercaptan, and hydrogen sulfide by immobilized Thiobacillus thioparus TK-m. J. Ferment. Bioeng. 67: 280-285.

15) Wada, A., M. Shoda, H. Kubota, T. Kobayashi, Y. Katayama-Fujimura and H. Kuraishi. 1986. Characteristics of $\mathrm{H}_{2} \mathrm{~S}$ oxidizing bacteria inhabiting a peat biofilter. J. Ferment. Technol. 64: 161-167.

16) Zhang, L., M. Hirai and M. Shoda. 1991. Removal characteristics of dimethyl sulfide, methanethiol and hydrogen sulfide by Hyphomicrobium sp. I55 isolated from peat biofilter. J. Ferment. Bioeng. 72: 392-396. 